\title{
Atypical form of dural graft associated Creutzfeldt-Jakob disease: report of a postmortem case with review of the literature
}

\author{
K Kimura, A Nonaka, H Tashiro, M Yaginuma, R Shimokawa, R Okeda, M Yamada
}

\begin{abstract}
A postmortem case of an atypical form of dural graft associated Creutzfeldt-Jakob disease (CJD) is described. A 42 year old man developed progressive spastic paresis 163 months after a cadaveric dura mater graft. He presented with no myoclonus and very late occurrence of periodic synchronous discharges on EEG. The prion protein (PrP) gene was homozygous for methionine at the polymorphic codon 129. Neuropathological examination disclosed plaque-like PrP deposits with atypical distribution of synaptic PrP accumulations in the brain. This patient represents an atypical form of dural graft associated CJD characterised by unusual clinicopathological features.

(F Neurol Neurosurg Psychiatry 2001;70:696-699)
\end{abstract}

Infectious Diseases,

Tokyo Metropolitan

Bokutoh General

Hospital, Tokyo, Japan

K Kimura

Department of Internal Medicine

A Nonaka

H Tashiro

M Yaginuma

Department of Neuropathology, Medical Research

Institute, Tokyo

Medical and Dental

University, Tokyo,

Japan

R Shimokawa

R Okeda

Department of

Neurology, Kanazawa

University School of

Medicine, 13-1

Takara-machi,

Kanazawa 920-8640,

Japan

M Yamada

Correspondence to:

Professor M Yamada

m-yamada@

med.kanazawa-u.ac.jp

Received 21 June 2000 and in final form

6 December 2000

Accepted 12 December 2000
Keywords: cadaveric dura mater graft; CreutzfeldtJakob disease; prion protein; plaque

A considerable number of patients with Creutzfeldt-Jakob disease (CJD) have been reported to be associated with a cadaveric dura mater graft. ${ }^{1}$ The number of the dural graft associated cases was especially large in Japan; 67 such patients were reported in Japan during January 1985 to March $1999 .^{2}$ In most of the dural graft associated cases, the clinical and neuropathological pictures were similar to those of sporadic (idiopathic) cases of CJD, although cerebellar signs were the most frequent early presentation in the dural cases. ${ }^{1}$ However, some patients with dural graft associated CJD have been reported to have atypical clinical features, with plaque formation in the brain. ${ }^{3-6}$ The plaque morphology in some florid plaques, ${ }^{4-6}$ which have been described in the variant CJD (vCJD) recognised first in the United Kingdom. ${ }^{7}$ Here we describe a patient with an atypical form of dural graft associated CJD, showing unusual clinicopathological features.

Case report

A 42 year old man visited our hospital in February 1998 because of progressive right hemiparesis that had started 1 month before. patients has been reported to be identical with
In his medical history, he had had a pituitary adenoma with pituitary apoplexy and underwent an operation with a cadaveric dural graft in June 1984. The pituitary apoplexy was complicated by subarachnoid haemorrhage, which caused vasospasm resulting in infarction in the area of the left anterior cerebral artery. We have no further information about the dural graft. When he left the hospital, he had slight right hemiparesis; later he had no apparent paresis and no difficulty in activities of daily living. On neurological examination in February 1998, he was alert and oriented. The right upper and lower limbs were spastic. Although he had difficulty due to the right spastic hemiparesis, he could walk with help. There were no remarkable findings on cranial CT, MRI, or cerebral angiography, except for the old infarction in the area of the left anterior cerebral artery. Thereafter, dysarthria, dysphagia, and left spastic hemiparesis appeared. Then he became unable to walk and also showed urinary and bowel incontinence. On admission to our hospital in September 1998, he could answer to questions with only one or two words, but could respond to complicated commands. He could eat by himself and sit on a chair although he was unable to stand. He showed horizontal nystagmus, marked spasticity, and weakness in the bilateral upper and lower extremities with bilateral pyramidal signs. Ataxia was not evident. No involuntary movement was found. Laboratory tests were normal, except for low concentrations of serum sodium $(125 \mathrm{mmol} / \mathrm{l})$, which was compatible with the syndrome of inappropriate antidiuretic hormone secretion (SIADH), and low concentrations of some pituitary hormones that were related to the postoperative state of the pituitary tumour. Analysis of CSF was normal, except for increased concentrations of neuron specific enolase (NSE) $(26 \mathrm{ng} / \mathrm{ml})$ and the presence of 14-3-3 protein. Brain CT and MRI showed only the old infarction of the left anterior cerebral artery territory as found in February 1999; except for that, there was no atrophy or abnormal intensity even on MRI diffusion images. EEG showed slow activity without periodic synchronous discharges. Prion protein $(\mathrm{PrP})$ gene analysis ${ }^{8}$ of the DNA extracted from the blood disclosed no mutation in the 

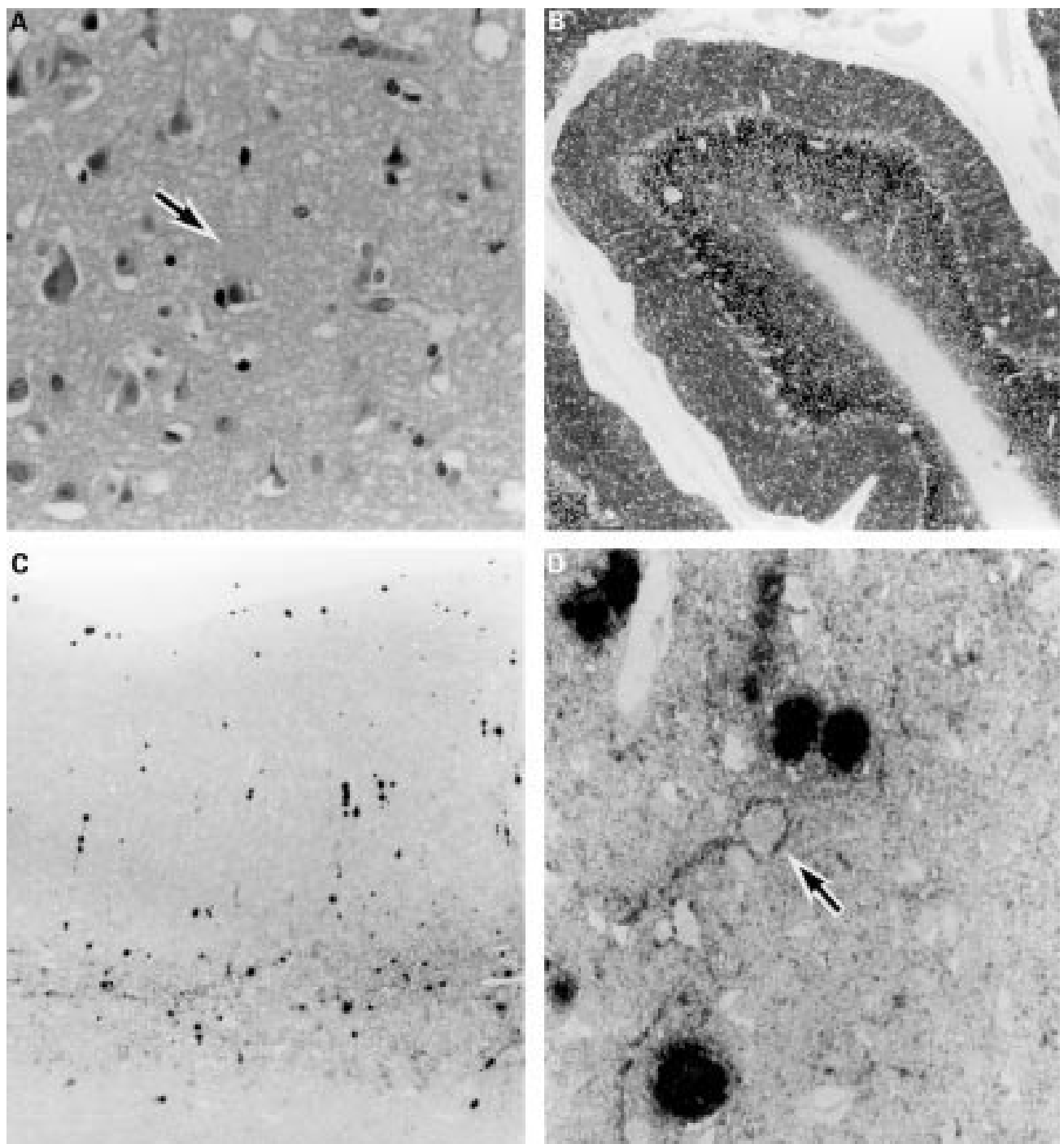

Figure 1 Neuropathological findings. (A) Mild spongiform change with shrinkage of neurons and mild astrocytosis in the cerebral frontal cortex; it is difficult to find plaque-like structures (arrow) (haematoxylin and eosin originally $\times 340$ ). (B) Immunohistochemistry with anti-PrP monoclonal antibody $3 F 4$ (originall $\times 34$ ); intense $\operatorname{Pr} P$ immunoreactivities of the synaptic type are found in the cerebellar cortex. (C) Cerebral frontal cortex; the plaque-type PrP deposits are scattered with granular PrP immunoreactivities of the synaptic type mainly in the 5th and 6th layers (PrP originally $\times 34)$. (D) Higher magnification of the deep layers of the frontal cortex shows plaque-type PrP deposits and granular PrP immunoreactivities of the synaptic type with a characteristic perineuronal staining (arrow) (PrP originally $\times 340)$.

open reading frame of the PrP gene. For the polymorphic codons, codon 129 was Met/Met, and codon $219 \mathrm{Glu} / \mathrm{Glu}$. The diagnosis was possible CJD. After admission, he progressively deteriorated to the status of akinetic mutism after several weeks. He died of bronchopneumonia in February 1999, 13 months after the onset of the symptoms. The findings on CT and MRI were unchanged throughout his course. In repeated EEG studies, periodic synchronous discharges were first recorded 2 days before his death. At necropsy, a patch of the dural graft was found in the right frontal region. The brain weighed $1275 \mathrm{~g}$. Macroscopically, the brain was slightly swollen and showed old cystic infarction scars in the territory of the left anterior cerebral artery with slight atrophy of the left cerebral hemisphere and right cerebellar hemisphere, and several, up to $10 \mathrm{~mm}$ sized, old infarction scars. Microscopically, there was mild to moderate spongiform change, neuronal loss, and astrocytosis in the cerebral cortex, especially in the paramedian cortical regions, subcortical grey matter, and brain stem (figure $1 \mathrm{~A}$ ). !mmunohistochemistry for PrP showed extensive accumulation of $\mathrm{PrP}$ in the brain; the $\mathrm{PrP}$ immunoreactivities, which were mainly granular (the synaptic type), were particularly intense in the cerebellar cortex and nuclei, brainstem nuclei (especially the inferior olivary nuclei), and cerebral deep grey matter (figure $1 \mathrm{~B}$ ). In the cerebral cortex, the PrP distribution was not uniform showing accentuation in the paramedian cortical regions including the cingulate gyrus and parahippocampal gyrus; the PrP immunoreactivities were relatively weak in the cerebral convexity regions, where the deposits were mainly in the 5th and 6th layers (figure $1 \mathrm{C}$ ). In the cerebral cortex, especially in the deep layers, plaque-like PrP deposits were found in addition to the granular PrP immunoreactivities of the synaptic type (figure $1 \mathrm{D})$. The plaque-like PrP deposits were unicentric and 
Table 1 Summary of patients with an atypical form of dural graft associated Creutzfeldt-Fakob disease (CFD)

\begin{tabular}{|c|c|c|c|c|c|c|c|c|c|c|c|c|}
\hline \multirow[b]{2}{*}{ No (authors) } & \multirow[b]{2}{*}{$\begin{array}{l}\operatorname{Agel} \\
\operatorname{sex}(y)\end{array}$} & \multirow[b]{2}{*}{$\begin{array}{l}\text { Dural graft } \\
\text { (y/origin) }\end{array}$} & \multirow[b]{2}{*}{$\begin{array}{l}\text { Latency } \\
\text { (y) }\end{array}$} & \multirow[b]{2}{*}{$\begin{array}{l}\text { Initial } \\
\text { symptom }\end{array}$} & \multirow[b]{2}{*}{ Myoclonus } & \multirow[b]{2}{*}{$\begin{array}{l}P S D s \\
o n \\
E E G\end{array}$} & \multirow[b]{2}{*}{$\begin{array}{l}\text { Clinical } \\
\text { course } \\
\text { (months) }\end{array}$} & \multicolumn{3}{|c|}{ Neuropathological findings } & \multicolumn{2}{|c|}{$\operatorname{PrP}$ genotype } \\
\hline & & & & & & & & $\begin{array}{l}\text { Brain } \\
\text { weight } \\
(g)\end{array}$ & $\begin{array}{l}\text { Spongifo } \\
\text { rm } \\
\text { change }\end{array}$ & Plaques & $\begin{array}{l}\text { Codon } \\
129\end{array}$ & $\begin{array}{l}\text { Codon } \\
219\end{array}$ \\
\hline 1 (Lane $\left.e t a l^{\beta}\right)$ & $28 / \mathrm{F}$ & 1984/Lyodura & 6 & Ataxia & - & - & 18 & 1200 & + & Kuru-type amyloid plaques & NA & NA \\
\hline $2\left(\right.$ Kopp et $\left.a l^{4}\right)$ & $52 / \mathrm{M}$ & 1984/unknown & 11 & Ataxia & - & - & 5 & NA & + & Florid-type PrP plaques & $\mathrm{Met} / \mathrm{Met}$ & NA \\
\hline 3 (Takashima $e t a \bar{l}$ ) & $47 / \mathrm{F}$ & 1985/Lyodura & 9 & Ataxia & + & - & 17 & 1220 & + & Florid-type PrP plaques & $\mathrm{Met} / \mathrm{Met}$ & $\mathrm{Glu} / \mathrm{Glu}$ \\
\hline $\begin{array}{l}4 \text { (Shimizu et al }{ }^{6}, \\
\text { case } 1)\end{array}$ & $68 / \mathrm{M}$ & $\begin{array}{l}\text { 1985/Lyodura } \\
\text { or Tutoplast }\end{array}$ & 11 & Ataxia & - & - & 7 & 1260 & + & Florid-type PrP plaques & Met/Met & Glu/Glu \\
\hline $\begin{array}{l}5 \text { (Shimizu et al } \\
\text { case } 2)\end{array}$ & $68 / \mathrm{F}$ & $\begin{array}{l}\text { 1986/Lyodura } \\
\text { or Tutoplast }\end{array}$ & 10 & Ataxia & - & $+^{\star}$ & 15 & 1055 & + & Florid-type PrP plaques & Met/Met & Glu/Glu \\
\hline 6 (this case) & $42 / \mathrm{M}$ & 1984/unknown & 14 & $\begin{array}{l}\text { Spastic } \\
\text { paresis }\end{array}$ & - & $+^{\star}$ & 13 & 1275 & + & Plaque-like PrP deposits & Met/Met & Glu/Glu \\
\hline
\end{tabular}

*Very late occurrence of periodic synchronous discharges (PSDs) on EEG. NA=information not available.

faintly eosinophilic with no or slight congophilia, suggesting that most of the plaquelike deposits would represent a preamyloid (non-fibrillary) form of PrP. Although some of the plaque-like PrP deposits were adjacent to spongiform changes, they were not surrounded by a distinct halo of spongiform change, and did not fulfil the criteria for florid plaques. In addition, there were PrP deposits surrounding neuronal cell bodies and processes in the cerebral cortex. A western blot analysis of protease resistant $\operatorname{PrP}$ with anti-PrP monoclonal antibody 3F4 disclosed a type 1 three band pattern showing no difference between this patient, dural graft associated patients without plaque-like PrP deposits, and patients with sporadic (idiopathic) CJD (data not shown).

\section{Discussion}

Our patient was characterised clinically by progressive spastic paresis (bilateral hemiparesis) which appeared 163 months after the neurosurgical operation with cadaveric dural grafting, and pathologically by atypical distribution of the PrP accumulations with PrP plaques. In the literature, there are two forms of dural graft associated CJD depending on the clinicopathological features. One is a common form showing clinicopathological features almost identical with classic presentations of sporadic (idiopathic) $\mathrm{CJD}^{1}$; dementia, ataxia, myoclonus, and other neurological abnormalities subacutely develop with periodic synchronous discharges on EEG in a relatively early phase of the clinical course, and show akinetic mutism in a few months; neuropathologically, granular PrP deposits of synaptic type are distributed mainly in the cerebral cortical and subcortical grey matter and cerebellar cortex without $\operatorname{PrP}$ plaques. The other is an atypical form characterised by unusual clinical and pathological features, different from the classic cases of CJD; so far, six patients with the atypical form of dural graft associated CJD have been reported including our patient (table 1)..$^{3-6}$ They are characterised clinically by relatively slow progression of neurological disorders such as ataxia and mental deterioration with a longer clinical course, no or late occurrence of myoclonus and periodic synchronous discharges on EEG, and no or slight progression of brain atrophy on CT/MRI. Pathologically they are characterised by the presence of $\operatorname{PrP}$ plaques, which have been in some cases been described as florid plaques, and atypical distribution of PrP deposits as found in our patient. For the genotype of PrP gene or western blot analysis of the protease resistant PrP with 3F4, no difference has been reported between the common form and atypical form of dural graft associated CJD, including our patient. ${ }^{6} \mathrm{Al}-$ though our patient shares several features with the previously reported cases of the atypical form of dural graft associated $\mathrm{CJD},{ }^{3-6}$ the following points are unique. Firstly, the main clinical presentation was progressive spastic paresis in our patient; by contrast, progressive ataxia is a common feature in the other reported cases (table 1) ${ }^{3-6}$ It is noteworthy that our patient previously had an area of old infarction in the left cerebral hemisphere and the dural graft in the right frontal region, and that, when the CJD developed, the patient initially showed right spastic hemiparesis and later progression to bilateral spastic hemiparesis. This suggests that the previous neurological deficit, but not the site of the dural graft, might have influenced the initial presentation of the subsequent CJD. In the five reported cases showing progressive ataxia, ${ }^{3-6}$ the sites of the dural grafts were variable including supratentorial (three cases) and infratentorial regions (two cases); it seems unlikely that the site of the dural graft would determine the phenotype of the subsequent CJD. Secondly, the plaque-like PrP deposits in the brain from our patient were mostly non-fibrillary plaques and morphologically different from florid plaques; by contrast, florid type PrP plaques ${ }^{4-6}$ and Kuru-type amyloid plaques $^{3}$ have been described in the reported patients with the atypical from of dural graft associated CJD. We emphasise that dural graft associated CJD may present with various clinical manifestations and neuropathological findings that are different from the classic pictures of CJD. The pathogenesis of the atypical form of dural graft associated CJD may be related to difference(s) in unknown factors, including the prion "strain" of the infectious dural grafts, and the genetic backgrounds of the hosts other than the PrP genotype, such as genetic polymorphisms in apolipoprotein $\mathrm{E}$ or other related molecules. Further clinical and experimental studies are necessary to elucidate these.

This study was supported in part by a grant from the Research Committee of Slow Virus Infection (to MY) from the Ministry of Health and Welfare, Japan. We are grateful to Dr T Kitamoto for the western blot analysis. 
1 Lang CJG, Heckmann JG, Neundorfer B. Creutzfeldt-Jakob disease via dural and corneal transplants. $\mathcal{F}$ Neurol Sci 1998;160:128-39.

2 Japanese Committee of Creutzfeldt-Jakob Disease and Related Disorders (Chief: Sato T). Report 30 March 2000. Japan: Ministry of Health and Welfare, 2000. (In Japanese.)

3 Lane KL, Brown P, Howell DN, et al. Creutzfeldt-Jakob disease in a pregnant woman with an implanted dura mater graft. Neurosurgery 1994;34:737-40.

4 Kopp N, Streichenburger N, Deslys JP, et al. CreutzfeldtJakob disease in a 52-year-old woman with florid plaques. Lancet 1996;348:1239-40.
5 Takashima S, Tateishi J, Taguchi Y, et al. Creutzfeldt-Jakob disease with florid plaques after cadaveric dural graft in a disease with florid plaques after cadaveric

6 Shimizu S, Hoshi K, Muramoto T, et al. Creutzfeldt-Jakob disease with florid-type plaques after cadaveric dura mater disease with florid-type plaques after
grafting. Arch Neurol 1999;56:357-62.

7 Will RG, Ironside JW, Zeidler M, et al. A new variant of Creutzfeldt-Jakob disease in the UK. Lancet 1996;347: 921-5.

8 Yamada M, Itoh Y, Fujigasaki $\mathrm{H}$, et al. A missense mutation at codon 105 with codon 129 polymorphism of the prion protein gene in a new variant of Gerstmann-SträusslerScheinker disease. Neurology 1993;43:2723-4.

\section{HISTORICAL NOTE}

\section{Aphasia and Wernicke's arc}

Sextus Empiricus (about AD 200) is credited $^{1}$ with being the first person to use the word "aphasia", albeit in a philosophical sense. Carl Wernicke's studies on aphasia, published from 1874, are among the classics of clinical neurology. However, Benton and Joynt $^{2}$ suggest that Johann Schmidt in 1677 gave the first account of paraphasia and alexia. They also observed that:

"Almost all the clinical forms of aphasiacomplete motor aphasia, paraphasia, jargon aphasia, agraphia and alexia-had been described before 1800. The unawareness of defect which may accompany paraphasia and jargon aphasia had been noted, as well as the coincidence of aphasia and agraphia..."

After the studies of Gall ${ }^{3}$ in 1807, and Bouillaud, there were many exponents of a dynamic view of aphasia. Finkelnburg (1870) regarded speech disorders as part of a wider disturbance, which he called lack of symbolic representation. Word blindness and word deafness, described by Bastian, were disorders of perception, independent of speech defects.

Critical to Wernicke's concepts was his anatomical demonstration of an arc of cerebral matter, in which lesions would be associated with aphasia. ${ }^{4} \mathrm{He}$ distinguished three varieties ${ }^{5}$ that still form the broad foundation of modern nosology.

Sensory aphasia, Wernicke attributed to a lesion of the auditory centre, which abolished "sound-images", and so prevented the patient from understanding words and from recognising his owns defects of speech.

Destruction of the third frontal convolution caused motor (Broca's) aphasia, with loss of the images for articulated speech.

A lesion that destroyed the pathway between the two centres caused conduction aphasia, leading to misuse of words but no

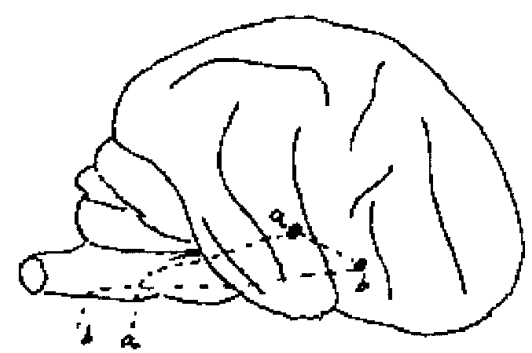

Wernicke's illustration of the arc, $1874^{4}$

defect of understanding. Moreover, a lesion destroying both centres caused loss of understanding both and expression of speechtotal aphasia.

The anatomical substrate lay in an arc in the dominant temporal lobe with linked fibres in the left third frontal convolution with central connections (figure). This was known as Wernicke's arc. He recognised that an auditory centre was in the first temporal convolution (Wernicke's area), and the centre for articulated speech in Broca's area. ${ }^{6}$

Broca had described: "aphemia . . .the result of a profound, but accurately circumscribed lesion of the posterior third of the second and third frontal convolutions." Trousseau in 1864 used the word aphasia ${ }^{7}$ to replace aphemia.

Later Broca distinguished two main speech disorders: aphemia, and verbal amnesia-in which the patient lost the memory not only of spoken but also of written wordscorresponding to Wernicke's receptive or sensory aphasia.

Both Dax ${ }^{8}$ and Broca had shown that loss of speech was caused by damage to the left half of the brain. But more penetrating analysis was left to Hughlings Jackson ${ }^{9}$ and others, who asked what was meant by loss of speech. $\mathrm{He}$ considered the importance of propositional versus emotional speech. The brain's levels of inhibition and disinhibition influenced the language content

The thesis of a precise anatomical localisation as the basis for focal symptoms proved controversial. Freud ${ }^{10}$ was critical of the "diagram makers", thus anticipating Head by
30 years. Freud thought that Wernicke's and Lichtheim's classifications corresponded neither to clinical or pathological facts. $\mathrm{He}$ recognised purely verbal, asymbolic, and agnostic varieties of aphasia. Goldstein's later studies ${ }^{11}$ were founded on Jacksonian concepts. Central, or in Wernicke's terminology - conduction aphasias, were seen as disorders of "inner speech". $\mathrm{He}$ regarded nominal aphasia as more than a loss of words, since, he said, it contained abnormal behaviour that any categorical action was disturbed.

Head (1926) also famously scorned the "diagram-makers" represented by Wernicke and others:

"They failed to appreciate that logical formulae of the intellect do not correspond absolutely to physical events, and that the universe does not exist as an exercise for the human mind ...

None the less, Wernicke's arc has proved an invaluable guide to clinical localisation of focal lesions affecting language and speech.

J M S PEARCE Beverley Road, Anlaby, East Yorks HU10 7BG

1 Benton AL, Joynt RJ. Early descriptions of aphasia. Arch Neurol 1960;3:205-9.

2 McHenry LC. Garrison's history of neurology. Springfield, Illinois: Thomas, 1969, reprint 1997:86.

3 Gall FJ. Craniologie ou dicouvertes nouvelles cancernant le cerveau le crane et les organes. Paris: Necelle, 1807.

4 Wernicke C. Der aphasische Symptomencomplex. Breslau: Tasehen, 1874

5 Wernicke C. Lehrbuch der Gehirnkrankheiten. Kassel and Berlin: Fischer, 1881

6 Broca PP. Remarques sur le siège de la faculté du language articulé suivie d'une observation d'aphemie. Bull Sac Anat Paris 1861:36:330-2.

7 Trousseau. A Lecture VII on aphasia. Lectures in Clinical Medinine 1868;1;218.

8 Dax M. Lésions de la moitié gauche de Dax M. Lesions de la moitie gauche de
l'encéphale coincident avec l'oubli des signes lencephale coincident avec l'oubli des signes de la pensée.

9 Jackson JH. In: Taylor J, ed. Selected writings of ¥H Fackson. Vol. 2. London: Staples Press, 1958.

10 Freud S. Zur Auffassung der Aphasien. Leipzig and Vienna; Deuliche, 1891. Translated by $\mathrm{E}$ Stengel, London, 1953.

11 Goldstein K. Language and language disturbances. New York, Grune and Stratton, 1948. 